\title{
Charcot Neuroarthropathy of the Foot and Ankle
}

\author{
Banskota B; Bijukachhe B; Shrestha BK; Banskota AK ${ }^{1}$
}

B\&B Hospital, Kathmandu University

\section{INTRODUCTION:}

Charcotneauroarthropathy is a non-infective, destructive process activated by an isolated or a cumulative neurotraumatic stimulus that manifests as dislocation, periarticular fracture, or both in patients rendered insensate by peripheral neuropathy ${ }^{1}$. Jean-Marie Charcot, the famous French neurologist, published his report on a destructive arthritis that affected patients with tertiary syphilis in 1868 and set the ball rolling for a gradual understanding of this complex, enigmatic and challenging clinical entity ${ }^{2}$. Neuroarthropathy secondary to diabetes mellitus is the commonest cause. Although it is quite correctly assumed that that Charcot neuroarthropathy has a negative effect on the quality of life of the patient, a targeted evidence body in relation to the foot related morbidity in diabetics is scanty ${ }^{3}$. Interestingly, several studies have shown a persistent negative health-related quality of life in patients treated successfully for their Charcoat condition ${ }^{4,5}$ implying a complex metabolic phenomenon that eventually culminates in to a clinical picture we know as Charcot neuroarthropathy.

\section{AETIOPATHOGENESIS:}

Peripheral neuropathy secondary to diabetes mellitus is the commonest cause but other conditions like leprosy, syphilis, alcoholism, rheumatoid arthritis, multiple sclerosis, syringomyelia and trauma can be associated with Charcot neuroarthropathy ${ }^{1}$. Around $12 \%$ of diabetic admissions are with foot problems. About $1 \%$ of diabetics eventually develop some degree of Charcot neuroarthropathy. They are usually insulin dependant diabetics in their $5^{\text {th }}$ or $6^{\text {th }}$ decades that've had the disease for over ten years.

There are two theories on the pathogenesis of joint destruction in Charcot neuroarthropathy. The neurotraumatic theory of Johnson ${ }^{6}$ proposes unrecognised repetitive microtrauma in an insensate extremity as the cause of neuroarthropathy whereas the neurovascular theory of Brower and Allman ${ }^{7}$ postulates an unregulated hyperemia secondary to autonomic neuropathy leading to increased osseous blood flow, increased osteoclastic activity, bone destruction and ligamentous weakness.

It is interesting to note that postsympathectomy patients do not necessarily develop neuroarthropathy and neuropathic patients who have had their fractures treated successfully are still at risk of neuroarthropathy ${ }^{8}$.

Baumhauer et al. identified an increased osteoclast to osteoblast ratio in the presence of multiple cytokines in their immunohistochemical study suggesting the role of complex humoral mechanisms in the pathogenesis of neuroarthropathy'.

It is probably a combination of the above two theories, supported by humoral and other factors that are as yet unknown, that interplay to produce Charcot neuroarthropathy in the susceptible individual.

In addition to the sensory neuropathy, a concomitant motor neuropathy leading to an imbalance between the dorsiflexors and plantarflexors of the foot an ankle coupled with a contracted Achilles tendon generates a bending moment through the midfoot during the terminal stance phase of gait. This may be responsible for arch collapse and development of the rocker-bottom deformity associated with Charcot neuroarthropathy ${ }^{10}$, $11,12,13$.

Classification Systems:

Eichenholtz Classification ${ }^{16}$ :

\begin{tabular}{ll}
\hline Stage 1 & $\begin{array}{l}\text { Erythema, warmth, and swelling; Injuries } \\
\text { of bone and joints e.g. healing fractures; } \\
\text { (development- } \\
\text { fragmentation): }\end{array}$ \\
$\begin{array}{l}\text { Red, hot and swollen foot often confused } \\
\text { with infection }\end{array}$ \\
Stage 2 & $\begin{array}{l}\text { Progressive bone destruction, new bone } \\
\text { formation, subluxation/ dislocation; Foot } \\
\text { collapses, arch flattens, rocker-bottom } \\
\text { appearance }\end{array}$ \\
Stage 3 & $\begin{array}{l}\text { Deformity consolidates to become fixed } \\
\text { and stable; May create pressure points for }\end{array}$ \\
(reconstruction- & ulceration \\
consolidation): &
\end{tabular}

Brodsky's anatomical classification ${ }^{17,18}$ : 
This classification helps us predict outcome, especially with regards to complications of the Charcot event.

\begin{tabular}{ll}
\hline Type 1: & $\begin{array}{l}\text { Involving all or parts of the Lisfranc (tarsometatarsal) } \\
\text { joints; most common type }(60-65 \% \text { of cases); } \\
\text { associated with plantar and medial exostoses; fastest } \\
\text { healing. }\end{array}$ \\
Type 2: & $\begin{array}{l}\text { Involves the transverse tarsal (Chopart), subtalar, } \\
\text { or all three joints of the hindfoot; } 30-35 \% \text { of cases; } \\
\text { higher incidence of instability; may have complete } \\
\text { medial or lateral subtalar dislocations. }\end{array}$ \\
Type 3A: & $\begin{array}{l}\text { Involves the ankle; residual ankle varus/valgus } \\
\text { deformity }+ \text { malleolar ulcers common }\end{array}$ \\
Type 3B: $\quad \begin{array}{l}\text { Involves the os calcis tubercle; least common type; } \\
\text { loss of calcaneal pitch, compromised longitudinal } \\
\text { arch, Achilles insuffieciency }\end{array}$ \\
\hline
\end{tabular}

All four types have three stages (A, B \& C) based on the degree of deformity on a lateral weight bearing radiograph.

Schön classification system ${ }^{19,20}$ : confused with cellulitis, abscess, osteomyelitis or gout. Elevating the affected extremity above the heart level for 5-10 mins should improve the dependent rubor associated with Charcot joint but doesn't affect erythema of infectious origin. A careful search for breach in the skin must be carried out to exclude a possible portal for infection ${ }^{19,20}$. There may be no recognizable injury leading to presentation or the patient may present with sprains, fractures, fracture-dislocations or pure dislocations. Although considered a painless process, Charcot patients may or may not have a history of pain ${ }^{9,10}$. Although many factors like obesity, peripheral vascular disease and osteopenia are thought to predispose to Charcot arthropathy, the lack of protective sensation is the only factor that has been found to be related to the onset of a Charcot event conclusively ${ }^{21,22}$. Using the SemmesWeinstein 5.07 monofilament, the inability to perceive a pressure of 10 grams applied to the skin is considered diagnostic of peripheral neuropathy ${ }^{19,23,24}$.

Based on anatomy plus severity of collapse

\begin{tabular}{lll}
\hline Type & Stage & Association \\
\hline The Lisfranc pattern & Deformity doesn't collapse to plantar surface of foot & Dislocation \\
The cuneonavicular pattern & $\begin{array}{l}\text { Deformity collapses and is coplanar to plantar surface } \\
\text { of foot } \\
\text { True rockerbottom foot; midtarsus inverted beneath } \\
\text { the forefoot and hindfoot }\end{array}$ & $\begin{array}{l}\text { Anteroposterior talar-first metatarsal angle of more } \\
\text { than } 35^{\circ}\end{array}$ \\
$\begin{array}{ll}\text { Lerinavicular pattern } \\
\text { The transverse tarsal }\end{array}$ & $\begin{array}{l}\text { Lateral fifth metatarsocalcaneal angle of } 0^{\circ} \text { of less } \\
\text { pattern }\end{array}$ &
\end{tabular}

\section{CLINICAL FEATURES AND DIAGNOSIS}

There are several systems used to classify Charcot neuroarthropathy. The Eichenholtz classification (Table 1) is based on radiographic stages with correlation to clinical appearance and helps us decide whether further casting or protected weight bearing is necessary. Brodsky's anatomical classification (Table 2) helps us predict outcome, especially with regards to complications of the Charcot event. Schon's classification assesses the severity of deformity and any associated subluxation or dislocation.

Presentation may be anywhere ranging from a red, swollen joint mimicking infection to a frankly dislocated and/or fractured extremity. The acute stage may be
Charcot neuroarthroarthropathy is a clinical diagnosis. Early radiographs are often normal and MRI and bone scan may be useful in picking up these early changes. Imaging techniques are useful for assessing the extent of damage and/or the presence of abscesses, but do not differentiate this condition from an evolving deep bone infection as the high-intensity signal observed in bone and periarticular soft tissues in Charcot neuroarthropathy is similar to that seen with infection. An infectious process is highly unlikely in the absence of an elevated white cell count, C-reactive protein and erythrocyte sedimentation rate but elevation of these parameters does not differentiate between various inflammatory processes. Blood glucose level provides information on glycaemic control. Technitium 99m scans combined 
NEPAL ORTHOPAEDIC ASSOCIATION JOURNAL (NOAJ)

VOLUME1, NUMBER ONE, JANUARY 2010
CHARCOT NEUROARTHOROPATHY OF THE FOOT AND ANKLE, Banskota B; Bijukachhe B; Shrestha BK; Banskota AK with labelled white cell scans may delineate the rare coexistence of neuroarthropathy and osteomyelitis ${ }^{20,25}$, $26,27,28,29$.

\section{MANAGEMENT}

The aim of treatment in early to intermediate Charcot neuroarthropathy (Eichenholtz stage 1 and 2) is prevention or containment of any deformity and associated skin problems until the lesion consolidates. Total contact cast (TCC) immobilization remains the mainstay of treatment for early stages (Eichenholtz stage 1) neuroarthropathy. TCC is continued and weight bearing avoided or limited until the fragmentation stage is complete. This is thought to prevent collapse of the vulnerable foot or exaggerate any existing deformity and hasten resolution of this stage. The resolution of tactile warmth is a reliable sign suggesting structural stability for transition to appropriate orthotics or brace $30,31,32,33,34$. If weight bearing is allowed, use of a rocker sole or a flat or rocker cast in addition to the TCC significantly reduces pressure on the midfoot ${ }^{35}$. Alternatives such as a prefabricated pneumatic walking boot have been proposed but may lead to increased heel pressure during walking predisposing to or worsening existing heel ulcers $^{36,37}$. The main complication of TCC is ulceration which was $5.5 \%$ in one study ${ }^{38}$.

There is very little evidence to support the role of any operative intervention for stage 1 neuroarthropathy. Simon et al. reported favourable results following debridement, open reduction and internal fixation and autologous bone grafting for Charcot event involving the Lisfranc comlex ${ }^{39}$. Reports for events involving the hindfoot and ankle are lacking as are studies comparing the results of operative intervention versus $\mathrm{TCC}^{21}$.

There is good evidence for the use of bisphosphonates in the treatment of early Charcot's neuroarthropathy ${ }^{40,41}$. This is aimed at reducing osteoclastic activity and the resultant bone weakness which is thought to play a major role in the evolution of this process. The role of bone growth stimulators in treatment of Charcots neuroarthopathy is not clearly established so far.

There is a much more defined role for operative management as the foot progresses to later stages (Eichenholtz stage 3) of the Charcot process. As discussed before, at this stage, arch collapse leads to skin compromise at the apex of any deformity with ulceration beneath bony prominences and the associated risk of infection which may eventually be limb-threatening. The role of accommodative footwear like the rockerbottom shoes for that deformity and the addition of an Ankle Foot Orthosis (AFO) or use of a Charcot Resistant Orthotic Walker (CROW) for neuroarthropathy involving the ankle has been investigated and supported by several retrospective studies $^{21,42,43,44,45,46,47}$. The key to healing in diabetic foot ulcer is relief of pressure and TCC seems to be the most effective currently available modality of treatment ${ }^{48}$.

With the increasing incidence of diabetes mellitus in our own society, it is more and more likely that we will be faced more frequently with the neuroarthropathic foot and ankle. An acutely swollen and warm foot in a diabetic patient may herald the presence of neuroarthopathy. The sequel of neuroarthropathy can largely be addressed nonoperatively; the total contact cast (TCC) having proven its efficacy. Surgical treatment is reserved for the nonhealing ulcer, infection, non-braceable deformity and fracture dislocations. The role of bisphosphonates though positive in producing clinical improvement, has not been fully established.

\section{REFERENCES}

1. Trepman, E; Nihal, A; Pinzur, MS: Current concepts review: Charcot neuroarthropathy of the foot and ankle. Foot Ankle Int. 26:46-63, 2005.

2. Charcot JM: On arthropathies of cerebral or spinal origin. Clin. Orthop. 296:4-7, 1993.

3. Connor, H: Diabetic Foot Disease - Where is the evidence? Diab. Med. 16: 799-800, 1999.

4. Dhawan, V; Spratt, KF; Pinzur, MS; et al.: Reliability of AOFAS diabetic foot questionnaire in Charcot arthropathy: stability, internal consistency and measurable difference. Foot Ankle Int. 26:717-731, 2005.

5. Pinzur, MS; Evans, A: Health related quality of life in patients with Charcot foot. Am. J. Orthop. 32:492-496, 2003.

6. Johnson JT. Neuropathic fractures and joint injuries. Pathogenesis and rationaile of prevention and treatment. J Bone Joint Surg Am. 1967; 49:1-30.

7. Brower AC, Allman RM. Pathogenesis of the neurotrophic joint: neurotraumatic vs. neurovascular. Radiology. 1981; 139:349-354. 
NEPAL ORTHOPAEDIC ASSOCIATION JOURNAL (NOAJ)

VOLUME1, NUMBER ONE, JANUARY 2010
CHARCOT NEUROARTHOROPATHY OF THE FOOT AND ANKLE, Banskota B; Bijukachhe B; Shrestha BK; Banskota AK
8. Schon LC, Marks RM. The management of neuroarthropathic fracture- dislocations in the diabetic patient. Orthop Clin North Am. 1995; 26:375-392.

9. Baumhauer, JF; O'Keefe, R; Schon, L; Pinzur, MS: Cytokine induced osteoclastic bone resorption in Charcot arthropathy: an immunohistochemical study. Foot Ankle Int. 27:797-800, 2006.

10. Armstrong, DG; Lavery, LA: Elevated peak plantar pressures in patients who have Charcot arthropathy. J. Bone Joint Surg. 80-A:365-369, 1998

11. Aronow, MS; Diaz-Doran, V; Sullivan, RJ: The effect of tricep surae contracture on plantar foot pressure distribution. Foot Ankle Int. 27:43-52, 2006.

12. Ledoux, WR; Schofer, JB; Ahroni, JH; et al.: Biomechanical differences among pes cavus, neutrally aligned, and pes planus feet in subjects with diabetes. Foot Ankle Int. 24:845850, 2003.

13. Mueller, MJ; Sinacore, DR; Hastings, MK; Strube, MJ; Johnson, JE: Effects of Achilles tendon lengthening on neuropathic plantar ulcers. J. Bone Joint Surg. 85-A: 14361445, 2003.

14. Eichenholtz, SN: Charcot Joints. C.C. Thomas, 1966.

15. Brodsky, JW: The Diabetic Foot. In Coughlin, MJ; Mann, RA (eds.): Surgery of the Foot and Ankle. Mosby, Inc., St.Louis, pp.895-969, 1999.

16. Brodsky J. Patterns of breakdown, natural history, and treatmentof the diabetic Charcot tarsus. Orthopaedic transactions. 1987; 11:484

17. Schon, LC; Easley, ME; Seinfeld, SB: Charcot neuroarthropathy of the foot and ankle. Clin. Orthop. 349: 116-131, 1998.

18. Schon, LC; Weinfeld, SB; Horton, GA; Resch, S: Radiographic and clinical classification of acquired midtarsus deformities. Foot Ankle Int.19:394-404, 1998.

19. Graves M; Tarquinio TA: Diabetic Neuropathy (Charcot Joints): The importance of recognising chronic sensory deficits in the treatment of acute foot and ankle fractures in diabetic patients; Orthopaedics; Apr 2003; 26, 4; pg.415.

20. Pinzur, MS: Current concepts review: Charcot arthropathy of the foot and ankle; Foot Ankle Int . 2007 Aug;28(8):952-9. Review

21. Armstrong, DG; Todd, WF; Lavery, LA; Harkless, LB; Bushman, TR: The natural history of acute Charcot's arthropathy in a diabetic foot specialty clinic. Diab. Med. 14:357-363, 1997.

22. Olmos, PR; Cataland, S; O’Dorisio, TM; Casey, CA; Smead,
WL; Simon, SR: The Semmes- Weinstein monofilament as a potential predictor of foot ulceration in patients with noninsulin-dependent diabetes. Am. J. Med. Sci. 309:76-82. 1995.

23. Veves, A; Uccioli, L; Manes, C; et al.: Comparison of risk factors for foot problems in diabetic patients attending teaching hospital outpatient clinics in four different European states. Diabetes Med. 11: 709-713, 1994.

24. Young, M; Breddy, JL; Veves, A; Boulton, AJM: The prediction of diabetic peripheral neuropathy using vibration perception thresholds: a prospective study. Diabetes Care. 17:557-560, 1994.

25. Bibbo, C; Lin, SS; Beam, HA; Behrens, FF: Complication of ankle fractures in diabetic patients. Orthop. Clin. North Am. 32:113-133, 2001.

26. Chantelau, E: The perils of procrastination: the effects of early vs. delayed detection of and treatment of incipient Charcot fracture. Diab. Med. 22:1707-1712, 2005.

27. Edmonds ME, Clark MB, Newton S, Barret J, Watkins PJ. Increased uptake of bone radiopharmaceutical in diabetic neuropathy. Q J Med. 1985; 57:843-855.

28. Keenan AM, Tindel NL, Alavi A. Diagnosis of pedal osteomyelitis in diabetic patients using current scintigraphic techniques. Arch Intern Med. 1989; 149:2262-2266.

29. Merkel KD, Brown ML, Dewanjee MK, Fitzgerald RH Jr. Comparison of indium-labelled-leukocyte imaging with sequential technetium-gallium scanning in the diagnosis of low-grade musculoskeletal sepsis. A prospective study. J Bone Joint Surgery Am. 1985; 67:465-476.

30. Armstrong, DG; Nguyen, HC; Lavery, LA; et al.: Offloading the diabetic foot wound: a randomized clinical trial. Diabetes Care 24:1019-1022, 2001.

31. Klenerman, L: The Charcot joint in diabetes. Diab. Med. 13:S520S54, 1996.

32 Lang-Stevenson, AL; Sharrard, WJ; Betts, RP; Duckworth, T: Neuropathic ulcers of the foot. J. Bone Joint Surg. 67-B: 438-442, 1985.

33. Lin, SS; Lee, TH; Wapner, KL: Plantar forefoot ulceration with equines deformity of the ankle in diabetic patients: the effect of tendo-achilles lengthening and total contact casting. Orthopaedics 19: 465-475, 1996.

34. Myerson, M; Papa, J; Eaton, K; Wilson, K: The total-contact cast for management of neuropathic plantar ulceration of the foot. J. Bone Joint Surg. 74-A: 261-269, 1992.

35. Dhalla, R; Johnson, JE; Engsberg, J: Can the use of a terminal device augment plantar pressure reduction with a total contact cast? Foot Ankle Int. 24: 500-505, 2003. 
NEPAL ORTHOPAEDIC ASSOCIATION JOURNAL (NOAJ) VOLUME1, NUMBER ONE, JANUARY 2010
CHARCOT NEUROARTHOROPATHY OF THE FOOT AND ANKLE, Banskota B; Bijukachhe B; Shrestha BK; Banskota AK
36. Bhaumhauer, f; wervey, R; McWilliams, J; Harris, GF; Shereff, MJ: A comparison study of plantar foot presuure in a standardized shoe, total contact cast, and prefabricated pneumatic walking brace. Foot Ankle Int. 26:26-33, 1997.

37. Hartsell, HD; Fellner, C; Saltzman, CL: Pneumatic bracing and total contact casting have equivocal effects on plantar pressure relief. Foot Ankel Int. 22:502, 2001.

38. Guyton, GP: An analysis of iatrogenic complications from the total contact cast. Foot Ankle Int. 26:903-907, 2005.

39. Simon, SR; Tejwani, SG; Wilson, DL; Santner, TJ; Denniston, NL: Arthrodesis as an alternative to nonoperative management of Charcot arthropathy of the diabetic foot. J. Bone Joint Surg. 82-A:939-950, 2000.

40. Jude, EB; Selby, PL; Burgess, J; et.al.: Bisphosphonates in the treatment of Charcot neuroarthropathy: a double-blind randomised control trial. Diabetologia. 44:2032-2037, 2001.

41. Pitocco, D; Ruotolo, V; Caputo, S; et.al.: Six-month treatment with alendronate in acute Charcot neuroarthropathy; a randomized controlled ttrial. Diabetes Care. 28:1214-1215,
2005.

42. Boninger, Ml; Leonard Jr., JA: Use of bi-valved anklefoot orthosis in neuropathic foot and ankle lesions. J. Rehab. Res. Dev. 33:16-22, 1996.

43. Mehta, JA; Brown, C; Sargeant, N: Charcot restraint orthotic walker. Foot Ankle Int. 19:619-623, 1998.

44. Morgan, JM; Biehl III, WC; and Wagner Jr, FWW: Management of neuropathic arthropathy with Charcot resistant orthotic walker. Clin. Orthop. 296:58-63, 1993.

45. Myerson, MS; Henderson, MR; Saxby, T; Short, KW: Management of midfoot diabetic neuroarthropathy. Foot Ankle Int. 15:233-241, 1994.

46. Pinzur, M: Surgical vs. accommodative treatment for Charcot arthropathy of the midfoot. Foot Ankle Int. 25:545-549, 2004.

47. A treatment algorithm for neuropathic (Charcot) midfoot deformity. Foot Ankle Int. 14:189-197, 1993.

48. Jeffcoate, W., Lima, J., Nobrega, L. (2000) The Charcot Foot. Diabetic Medicine, 17(4): pp.253-258.

\section{Figure Legends}
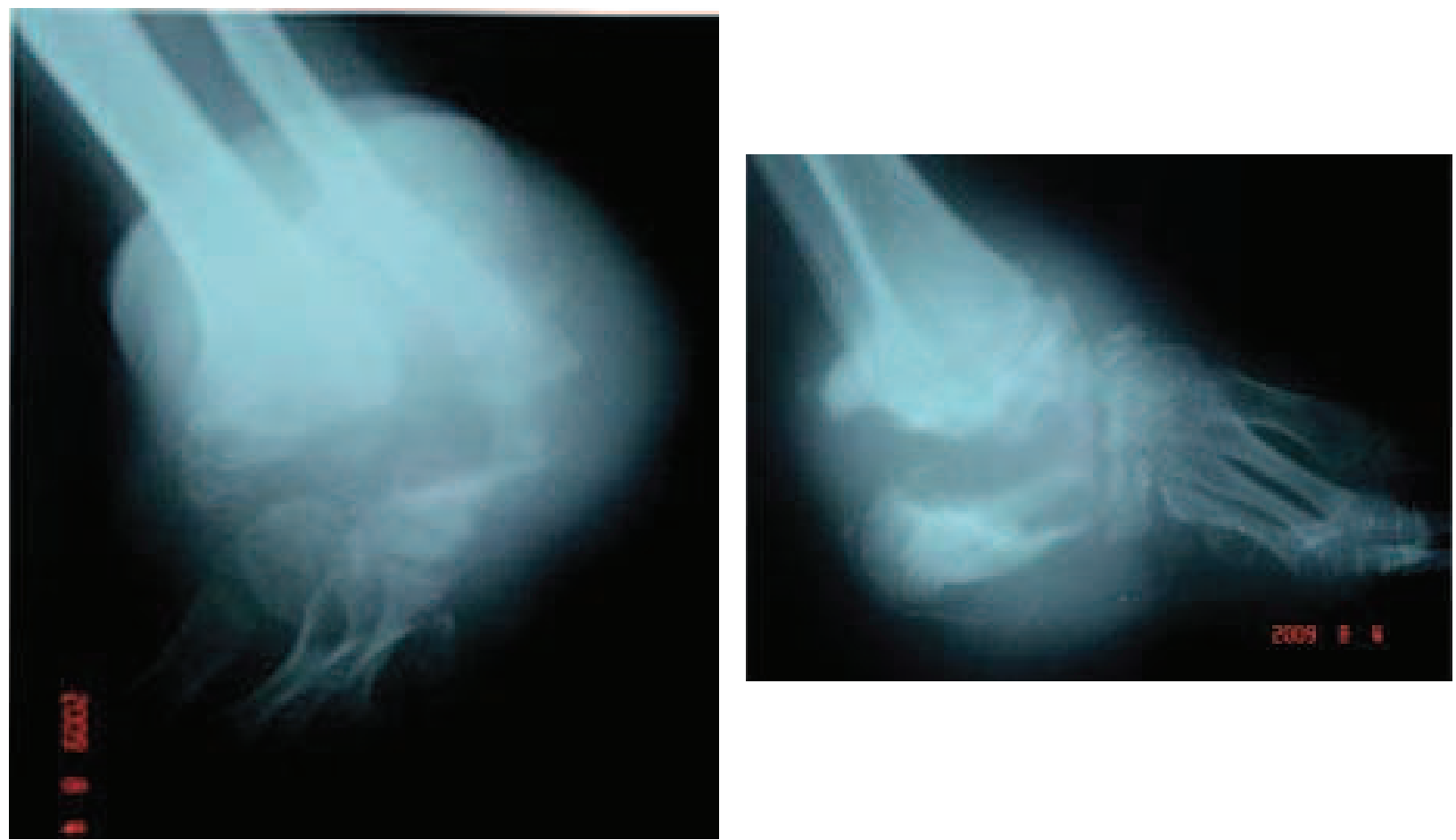

Fig $1 \& 2$ : AP and Lateral x-rays of the foot and ankle of a 13 year old girl with spina bifida showing typical Charcoat's joint showing near complete destruction of subtalar and midtarsal joints. 
NEPAL ORTHOPAEDIC ASSOCIATION JOURNAL (NOAJ)

VOLUME1, NUMBER ONE, JANUARY 2010
CHARCOT NEUROARTHOROPATHY OF THE FOOT AND ANKLE, Banskota B; Bijukachhe B; Shrestha BK; Banskota AK
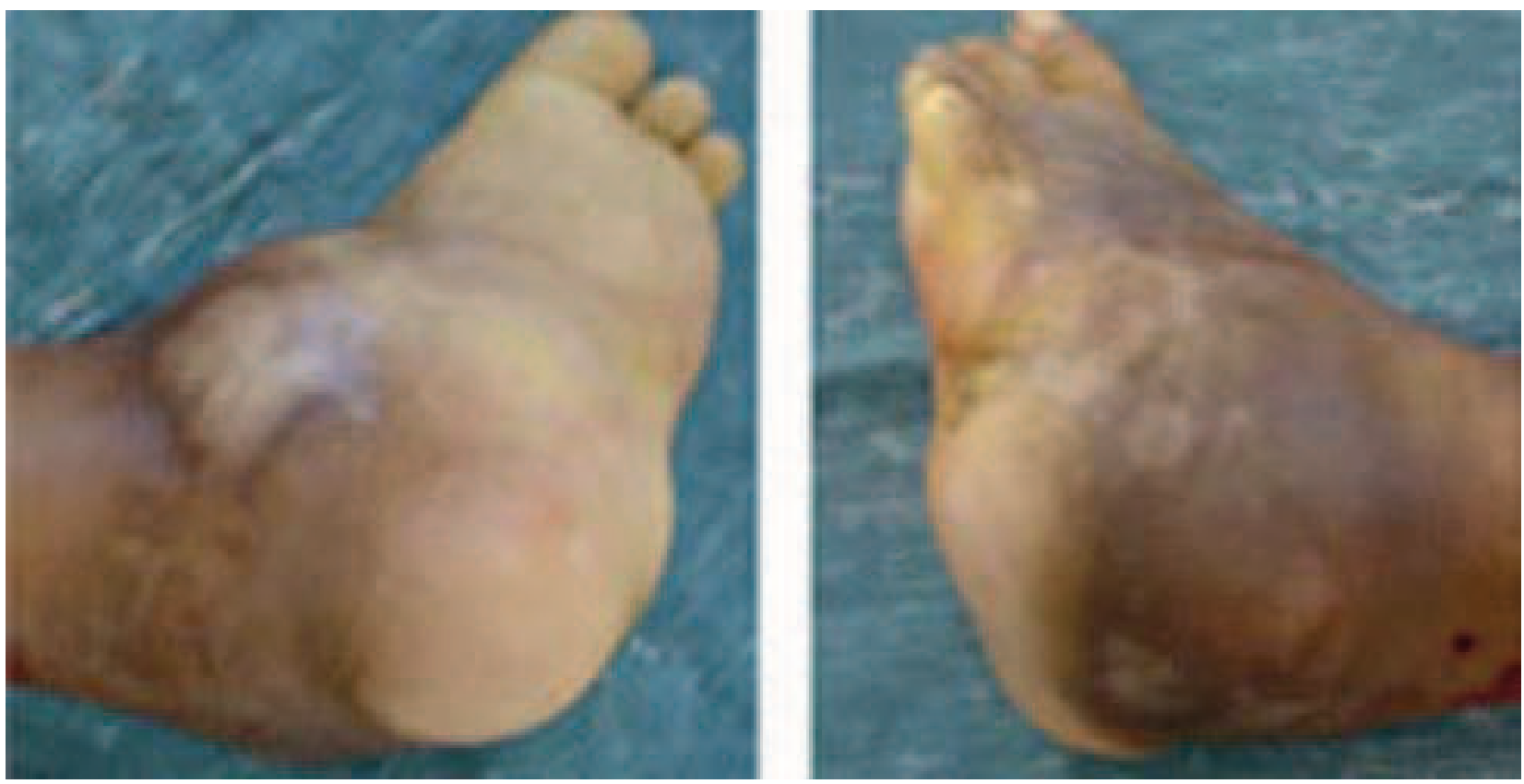

Fig $3 \&$ 4: Clinical picture of the same patient showing multiple scars indicating old ulcers. Note the rocker-bottom deformity of the foot. The foot and ankle up to the mid-calf areas were completely insensate. 